\title{
MARGINAL BONE LOSS AROUND MACHINED VERSUS PLASMA SPRAYED IMPLANT SUPPORTED MANDIBULAR OVERDENTURE CASES -A SPLIT- MOUTH RANDOMIZED CONTROLLED TRIAL
}

\author{
Maha Nagy Mohamed Kamal ${ }^{*}$
}

\begin{abstract}
Aim of this study: To compare marginal bone loss around machined and plasma sprayed dental implant collar surfaces after 24 months follow up period in mandibular overdenture cases.

Materials and methods: Eight patients with completely edentulous ridges received 32 implants; each patient received 4 implants at the lower arch; 2 machined collar implants were placed at one side and 2 plasma sprayed collar implants were placed at the other side. The implants were loaded 3 months after placement. Radiographic marginal bone loss was measured using CBCT at time of implant placement (baseline), 3,6,12 and 24 months follow up periods.
\end{abstract}

Result: Marginal bone loss was observed for both machined and plasma sprayed implant collars throughout the follow up periods with statistically significant decrease in bone level through 24 months follow up period.

Conclusion: Plasma sprayed implant collar promoted better bone repair with less bone loss than did machined implant collar.

KEY WORDS: Machined implant surface, plasma sprayed implant, marginal bone loss around implant, implant supported overdenture.

\section{INTRODUCTION}

Achieving optimal implant placement with preservation of bone integrity, bone health and successful osseointegration could be guaranteed by minimal trauma during osteotomy preparation, presence of implant primary stability, avoidance of infection and micromotion and maintenance of periimplant soft tissues in the best health conditions together with implant surface properties and type of surface treatment. ${ }^{[1]}$

Dental implant surface technology has been continuously developed over the past years from an osseointegrated surface with relatively smooth machined characteristics to an osteoconductive implant surface with more roughened characteristics. After implant placement, bone healing is directly

* Lecturer of Removable Prosthodontics Department, Faculty of Dentistry, British University in Egypt (BUE). 
affected by the condition of the implant surface. The rate of bone-to-implant contact depends on specific criteria, such as ionic composition of the metal alloy, topography, roughness, and energy on the implant surface. The chemical composition and topography of titanium implant surfaces play an important role in the osseointegration rate and its extension and directly influence the attraction and accommodation of bone cells toward the modified implant surface. ${ }^{2}$

To accelerate bone deposition around implant surface, several methods have been introduced to modify the contact between bone and implant surfaces, accelerate bone deposition and improve mineralization process of the osteoid matrix such as coating the titanium implant surface with hydroxyapatite or titanium plasma, acid etching, deposition of ionic components by biomimetic action, blasting with airborne particles, and anodization of implant surfaces. ${ }^{3-5}$

Titanium plasma spray (TPS) coating is fabricated by adding of pure titanium molten particles by plasma spraying technique over the implant surface. Some researchers have reported TPS-coated implants could result in a higher percentage of boneto implant contact (BIC) around implant surfaces and through their apical vents than implants with machined surfaces, on the other hand, some studies have reported the presence of fibrous tissue between the TPS surface and bone. Coating resorption of TPS implants is also reported, it may be related to the quality of the coatings studied which had low-density, low microhardness and showed microcracks with poor bonding strength between coating and implant. ${ }^{6}$

However, on the contrary, it was reported that after 3 years follow up period, implants with a very rough surface have a $20 \%$ increased risk of being affected by peri-implantitis. The difficulties in the treatment of peri-implantitis and the questionable long-term prognosis of implant cases affected by peri-implantitis, caused some doubts on the success of rough surface implants, in particular of those treated with titanium plasma-sprayed techniques, making the use of implants with machined surfaces more durable and interesting once again. ${ }^{8-11}$

The aim of this study was to compare the marginal bone loss around machined and plasma sprayed dental implant collar surfaces after 24 months follow up period in implant-supported mandibular overdenture cases

\section{MATERIALS AND METHODS}

Eight patients were scheduled to receive implant-supported overdenture in mandibular arch. The patients were included in the study if they fulfilled the following criteria: (1) presence upper and lower completely edentulous ridges. (2) minimum bone height $14 \mathrm{~mm}$ and minimum bone width $6 \mathrm{~mm}$ for implant placement without the need for bone augmentation surgery. (3) healed bone sites with at least 4 months having elapsed from the last tooth extraction (4) sufficient implant primary stability, with an insertion torque (IT) $\geq$ $35 \mathrm{Ncm}$. Patients with systemic diseases, such as osteoporosis, uncontrolled diabetes mellitus and hypertension were excluded from the study. Also, if the treatment would cause a risk to the patient's health, patient cooperation appeared questionable, and/or the patient did not consent to participate. Prior to entry into the study, each subject provided informed consent to participate.

Patient grouping: this was a split mouth study, each patient received four implants at the lower arch, 2 machined collar implants were placed at one side and 2 plasma treated implants (consists of double organic acid etching to generate macro and microtextured surface followed by cold plasma treatment and decontamination) were placed at the other side, both implant types were identical and had the same macroscopic design: internal connection, tapered, self-tapping and were made of titanium grade 4 . All implants were $3.7 \mathrm{~mm}$ diameter and 11.5 length. (Vitronex Elite Implants,Italy) Fig 1,2 


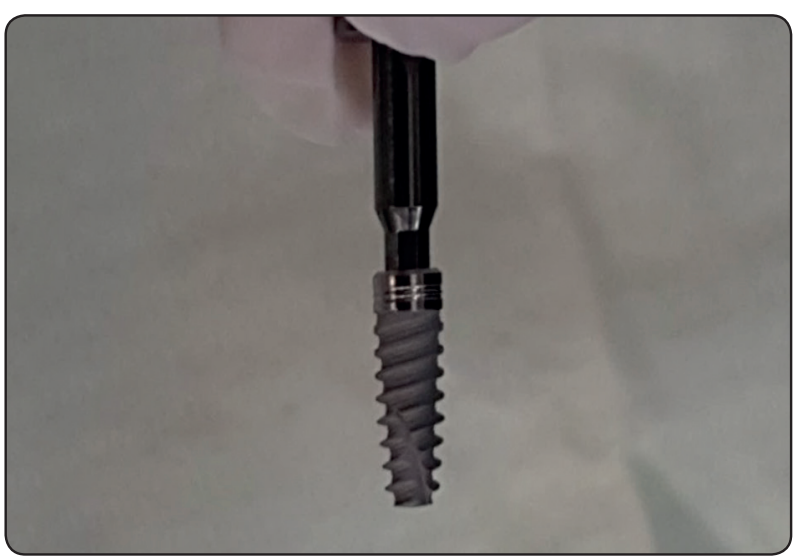

Fig. (1) machined implant collar

Sample allocation: Patients were randomly assigned into two identical groups by using special website concerned with randomization process called research randomizer (https://www.randomizer.org/)

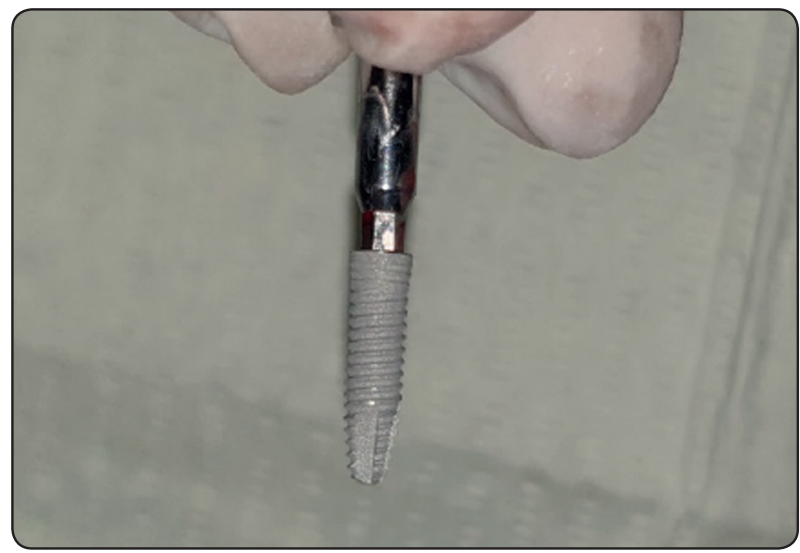

Fig. (2) plasma sprayed implant collar

Pre-operative radiographic imaging (CBCT Scan) was carried-out while the patient was wearing the radiographic template and biting on cotton rolls with the upper denture in place to stabilize the radiographic template. $\mathrm{CBCT}$ image was obtained in Digital Imaging and Communications in Medicine (DICOM) format. Fig. 3

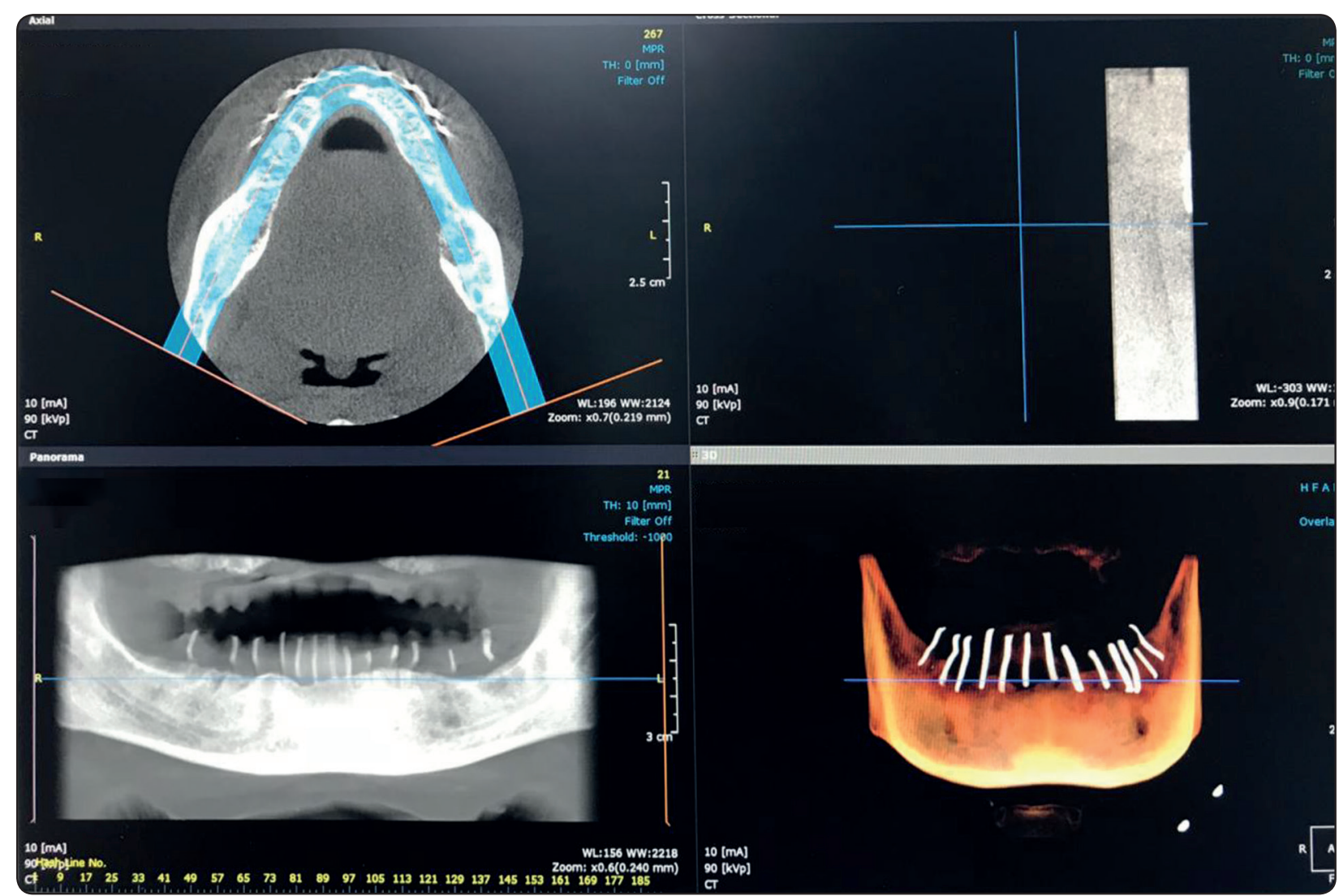

Fig. (3): per-operative CBCT with radiographic stent. 
Four Implants were virtually placed at mandibular lateral and first premolar area bilaterally using OnDemand3D software. The virtual surgical guide was designed with four holes to receive prefabricated metallic sleeves to guide implant installation. Additional three channels were added during the virtual planning for installation of anchoring screws. The position of these additional channels was made at the first molar region bilaterally and the third channel was placed in the midline. Fig. 4 Once the computer planning is accomplished, this plan is saved as a "STL" file format and sent to printing center for fabrication of the surgical guide using 3D printing machine (Rapid prototyping machine P380, EOS, Munich, Germany).

Implant Installation: Pre-medications include antibiotic (Clavulanate-potentiated Amoxicillin) $1 \mathrm{gm} / 12$ hours the day before surgery and continued for five days after. Anti-inflammatory (Diclofenac sodium 50mg) and Chlorhexidine mouth wash were prescribed 3 times daily prior to surgery. After checking the local anesthesia; The surgical stent was inserted into the patient's mouth; The maxillary complete denture was seated in place for stabilization of the surgical stent. Anchoring twist drill was utilized to drill into bone through the channels prepared in the surgical guide under copious irrigation. Three fixation screws were inserted into the previously prepared holes in the surgical. Fig 5

The upper denture was removed, and the osteotomy preparations were completed, the patient was randomized to receive either implants with a machined surface or with plasma sprayed surface by opening the corresponding sealed envelope containing the group allocation code. Implants were inserted through the osteotomy manually then continued using a ratchet until the implant top was flushed with the bone surface, then the covering screws were placed.

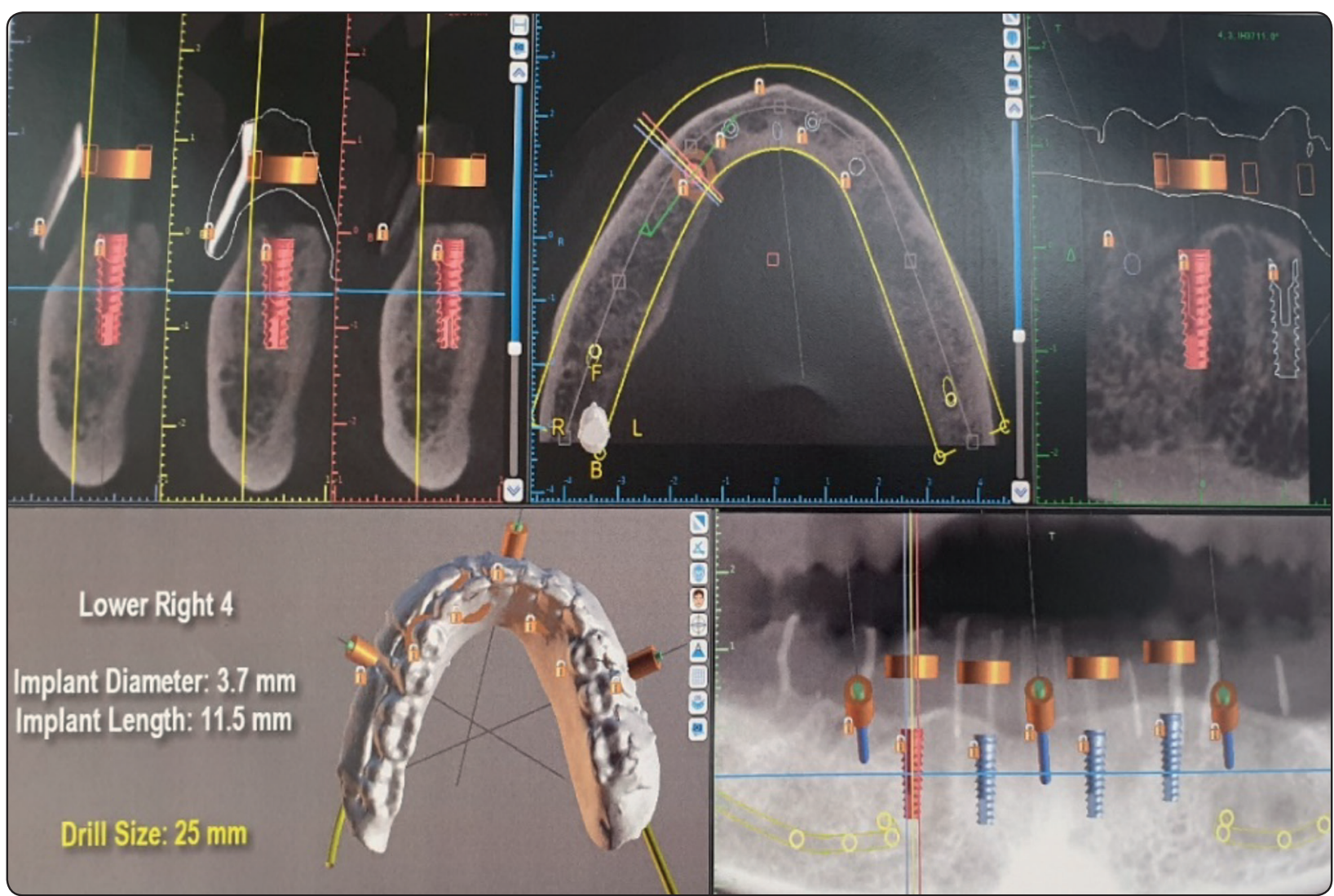

Fig. (4): virtual implant planning 
Radiographic measurements: CBCT image was taken at the day of implant insertion (baseline). For standardization: volume reorientation was done by making the long axis of the implant perpendicular on the axial reference line, while coronal plan standardization was assured by adjusting the coronal cut at the middle of the implant followed by drawing a line tangent to implant apex, bone length buccal and lingual to the implants was measured from the tangent line to the most crestal level of the bone in contact with the implant surfaces, finally sagittal plan standardization was done by adjusting the sagittal cut at the middle of the implant followed by drawing a line tangent to implant apex, Bone length mesial and distal to the implants was measured from the tangent line to the most crestal level of the bone in contact with the implant surfaces Fig

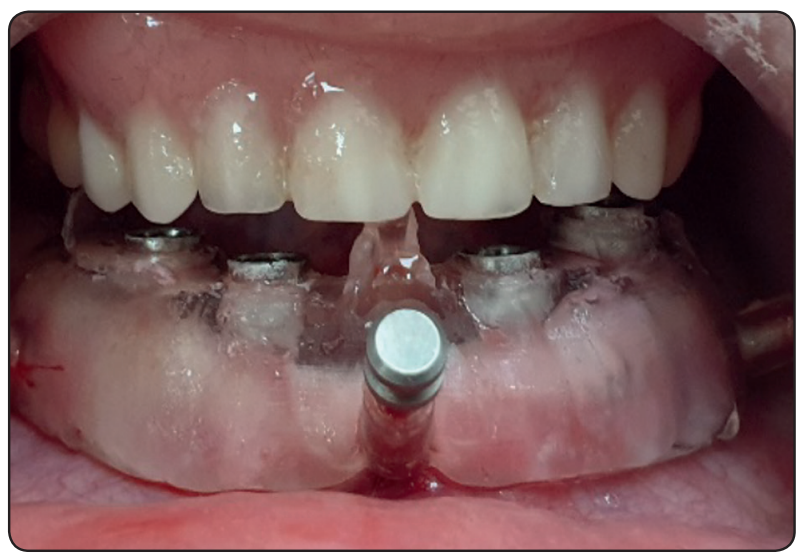

Fig. (5): surgical guide with fixation screws.

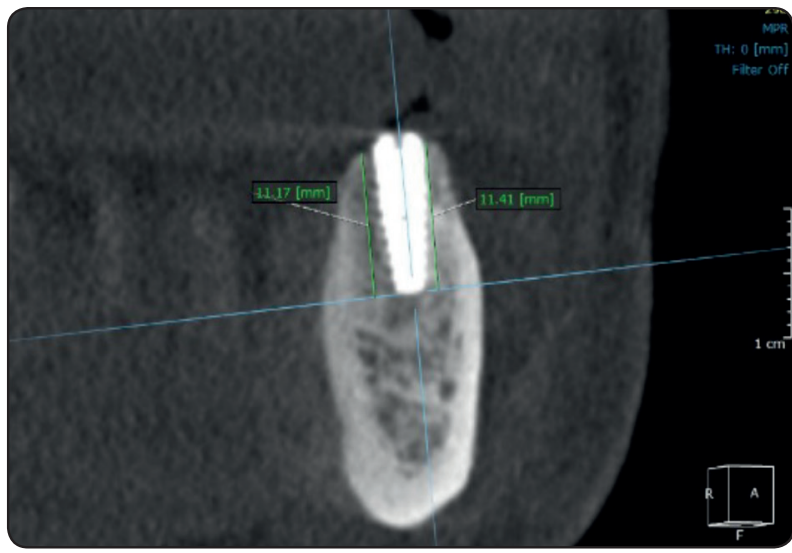

Fig. (6): CBCT with buccal and lingual bone height measurements around implant.
6. Another CBCT images were performed at 3,6,12 and 24 months using the same parameters and the same machine, marginal bone loss around implant collar surfaces throughout the follow up periods was calculated, tabulated and statistically analyzed.

Prosthetic phase: After three months of implant installation, patients were recalled for second stage surgery. The surgical stent was used to relocate the positions of the implants after anaesthetizing the patient. The ball attachments were inserted onto the implant fixture. Fig 8. After healing of the soft tissues surrounding the implants was completed. The metal housing of the attachment with the cap were placed over the male part of the attachment for the pick- up procedure.

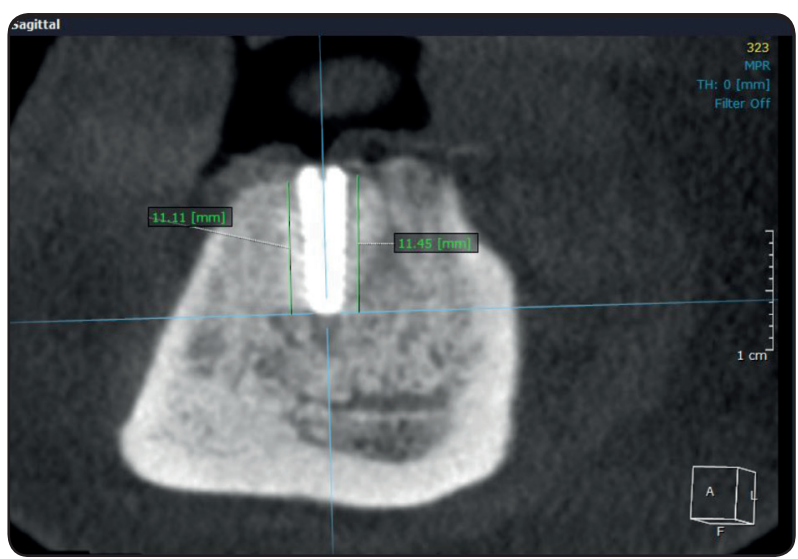

Fig. (7): CBCT with mesial and distal bone height measurements around implant.

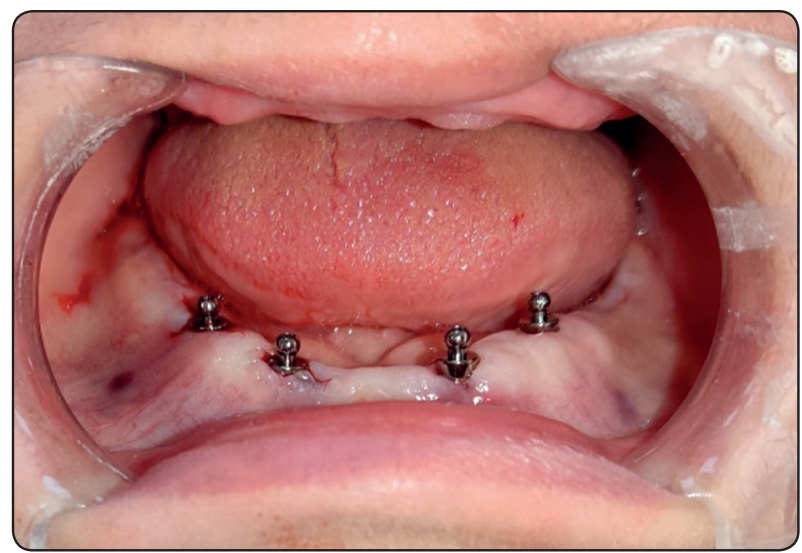

Fig. (8): healing around ball attachments. 


\section{RESULTS}

Statistical analysis was performed using IBM SPSS Statistics Version 2.0 for Windows. Data was presented as mean and standard deviation. The significance level was set at $\mathrm{P} \leq 0.05$. KolmogorovSmirnov and Shapiro-Wilk tests were used to assess data normality. One-Way ANOVA followed by Tukey's post-hoc test were used to compare the bone height at the different follow-up periods with each collar surface group. Independent t-test was conducted to compare the bone height between collar surface groups at each follow-up period.

\section{Effect of collar surface and follow-up period on bone height}

Independent t-test showed that there was a statistically significant higher bone height mean values of plasma sprayed collar surface implant group at 24 months $(\mathrm{P}=0.03$, respectively) compared to machined collar implant group. While there was no statistically significant difference in bone height between both collar surface groups at delivery, 3 months, 6 months, and 12 months $(\mathrm{P}=0.130$, $\mathrm{P}=0.257, \mathrm{P}=0.256$ and $\mathrm{P}=0.293$, respectively).

One-Way ANOVA and Tukey's test revealed that there was a statistically significant difference in bone height mean values between different follow-up periods within each collar surface group $(\mathrm{P}<0.001$ and $\mathrm{P}<0.001$, respectively).

Within both groups, the mean bone height was the highest at baseline, followed in descending order by 3 months, 6 months, 12 months and 24 months which yielded the significantly lowest bone height value. Table 1, Fig. 9.
TABLE (1): Mean \pm Standard Deviation of bone height $(\mathrm{mm})$ with each collar surface at different follow up periods.

\begin{tabular}{|c|c|c|c|}
\hline & Machined collar & $\begin{array}{c}\text { Plasma treated } \\
\text { collar }\end{array}$ & P-value \\
\hline Baseline & $11.57 \pm 0.01^{\mathrm{a}}$ & $11.56 \pm 0.01^{\mathrm{a}}$ & 0.130 \\
\hline $\mathbf{3}$ months & $11.34 \pm 0.03^{\mathrm{b}}$ & $11.30 \pm 0.04^{\mathrm{b}}$ & 0.257 \\
\hline $\mathbf{6}$ months & $11.01 \pm 0.07^{\mathrm{c}}$ & $10.94 \pm 0.09^{\mathrm{c}}$ & 0.256 \\
\hline $\mathbf{1 2}$ months & $10.49 \pm 0.03^{\mathrm{d}}$ & $10.43 \pm 0.10^{\mathrm{d}}$ & 0.293 \\
\hline $\mathbf{2 4}$ months & $9.64 \pm 0.06^{\mathrm{e}}$ & $9.77 \pm 0.04^{\mathrm{e}}$ & $0.003^{*}$ \\
\hline P-value & $<0.001$ & $<0.001$ & \\
\hline
\end{tabular}

*: significant at $P \leq 0.05$

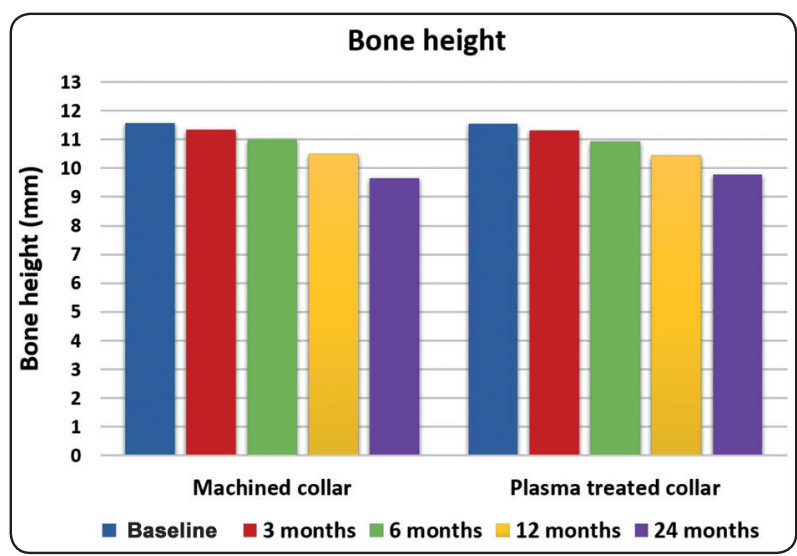

Fig. (9): Column chart showing the mean values of bone height $(\mathrm{mm})$ with each collar surface at different follow-up periods. vv

\section{DISCUSSION}

Implants with different collar geometry and surface treatment were used in the study, implants with smooth machined collar compared to irregular plasma sprayed implants which received plasma bio-active surface treatment. ${ }^{12}$

Results of this study showed lower bone loss values around plasma sprayed implant collar than machined collars from 3months to 24 months follow up period with statistically significant lower 
values at 24 month follow up period, this is may be explained by the presence of roughened surfaces have been shown to increase the area of bone to implant contact, promoting better peri-implant bone formation than the machined implant surfaces ${ }^{13}$. The macro- and microtopography of implant surfaces, as well as the specific surface structure of the oxides existed on the superficial layer of the implant have been shown to be extremely important factors in influencing osseointegration around implant collar positively ${ }^{14}$. This results agreed with results of other studies confirmed that numerous alterations of titanium implant surfaces have optimized and accelerate cellular and tissue interactions and thereby enhance earlier peri-implant bone deposition. ${ }^{15,16}$ Also, modification of physical and chemical properties resulting from surface treatments can be helpful in contact osteogenesis which is directly associated with adsorption of cellular proliferation, new proteins formation and bone matrix deposition. ${ }^{17}$

Marginal bone loss observed in the present study was less than $2 \mathrm{~mm}$ after 24 months follow up period in both groups which is considered as a physiologically acceptable level ${ }^{18}$.

An excellent survival rates were reported for titanium plasma sprayed (TPS-coated) implants exceeding $95 \%$ after 5 years to 11 years of clinical functioning, long-term predictability for TPS -coated implants can be comparable with or superior to other implant surfaces. ${ }^{6}$

However, another study was performed to compare the prosthetic and implant failures of immediately loaded single implants with a machined or a roughened surface (sand-blasted with zirconia powder and acid etched), both groups showed good and similar results with no statistically significant differences. ${ }^{11}$

Another study was done to evaluate the biologic response of titanium Implants with machined surface versus laser-Treated Surfaces, it revealed that the analysis of bone repair on the roughened laser- treated surfaces demonstrated direct contact between the bone (mineralized interfacial matrix) and the implant, suggesting mechanical penetration of the irregularities of the superficial roughness promoted by this surface morphology, as well as oxide layer modification. $^{2}$

In a meta-analysis included seven controlled randomized trials performed to point out whether implants with machined surface could be reliable alternative to implants with roughened surface over time or not, it was found that there were no statistically significant differences in early implant failures between implants with machined surfaces and implants with roughened surfaces, although patients lose more implants early with the machined surface than the rough implant surface group..$^{19-21}$ On the other hand a second meta-analysis included four rough surface treatments, showed that 3 years after loading, implants with machined surfaces had a statistically significant risk reduction of periimplantitis by $20 \%$. $2-25^{2-25}$

In a study done to evaluated the effect of implant macro-design and position on bone implant contact (BIC) and crestal bone level, results revealed that, sub-crestal positioned implants with crestal microthreads led to a relatively reduced crestal bone resorption and increased BIC compared to $2 \mathrm{~mm}$ sub-crestal positioned implants with no crestal micro-threads. The larger BIC values for implants placed sub-crestal suggest that bone regeneration may be more favorable when the implant surface is contained within the peri-implant bone rather than apically positioned implant which does not enhance remodeling of the bone crest. These results confirm by other previous animal studies done by Tran et al. ${ }^{26,27}$

It was stated that micro-threaded implant has higher compression and less shear stress at the crestal cortical bone adjacent to the implant and so can reduce marginal bone resorption. ${ }^{28-30}$ However, some scholars have different opinions that microthreads cannot improve marginal bone preservation, 
and there is no significant difference between implants with macro-threads and micro-threads in relation to marginal bone loss after loading (1 year or 12 years) with good oral hygiene and a stable gingival and periodontal status..$^{31-34}$

\section{CONCLUSION}

Within the limitation of the present study, it was concluded that plasma sprayed rough implant collar surface promoted better bone repair with less marginal bone loss than did machined implant collar surface.

\section{REFERENCES}

1. CapHla MV, Oiid MR, Gaya MO, Botella CR and Romera CZ. Cylindrical Dental Implants With Hydroxyapatite and Titanium Plasma Sprayed -Coated Surfaces: 5-Years Results. J Oral Implanto. 2007; 33 (2): 59-68.

2. Allegrini Jr S, Yoshimoto M, Salles MB and Bressiani AH. Biologic Response to Titanium Implants with Laser-Treated Surfaces. Int J Oral Maxillofac Implants. 2014;29:63-70.

3. Simon M, Lagneau C, Moreno J, Lissac M, Dalard F, Grosgogeat B. Corrosion resistance and biocompatibility of a new porous surface for titanium implants. Eur J Oral Sci 2005 Dec;113(6):537-545.

4. Le Guéhennec L, Soueidan A, Layrolle P, Amouriq Y. Surface treatments of titanium dental implants for rapid osseointegration. Dent Mater 2007;23:844-854.

5. Junker R, Dimakis A, Thoneick M, Jansen JA. Effects of implant surface coatings and composition on bone integration: A systematic review. Clin Oral Implants Res 2009 Sep;20(suppl 4):185-206.

6. CapHla MV, Oiid MNR, Gaya MVO, Botella CR, Romera CZ. Cylindrical Dental Implants with Hydroxyapatite and Titanium Plasma Spray- coated Surfaces: 5-Years results. J Oral Imp. 2007; 33 (2): 59-68

7. Esposito M, Ardebili Y, Worthington HV. Interventions for replacing missing teeth: different types of dental implants. Cochrane Database Syst Rev 2014; 22:7:CD003815.

8. Leonhardt A, Dahlen G, Renvert S. Five-year clinical, microbiological, and radiological outcome following treatment of peri-implantitis in man. J Periodontol 2003; 74: 1415-1422.
9. Esposito M, Grusovin MG, Worthington HV. Interventions for replacing missing teeth: treatment of peri-implantitis. Cochrane Database Syst Rev. 2012; 18:1: CD 004970.

10. Ottoni JM, Oliveira ZF, Mansini R, Cabral AM. Correlation between placement torque and survival of singletooth implants. Int J Oral Maxillofac Implants 2005; 20: 769-776.

11. Cannizzaro G, Leone M, Ferri V, Viola P, Gelpi F, Esposito M. Immediate loading of single implants inserted flapless with medium or high insertion torque: a 6-month followup of a split-mouth randomized controlled trial. Eur J Oral Implantol. 2012; 5: 333-342.

12. http://www.vitronex.it/en/products/1-surface-treatment

13. Anselme K, Bigerelle M, Noël B, Iost A, Hardouin P. Effect of grooved titanium substratum on human osteoblastic cell growth. J Biomed Mater Res 2002 Jun;60(4):529-540.

14. Xiropaidis AV, Qahash M, Lim WH, et al. Bone-implant contact at calcium phosphate-coated and porous titanium oxide (TiUnite)- modified oral implants. Clin Oral Implants Res 2005;16:532-539.

15. Lossdorfer S, Schwartz Z, Wang L, et al. Microrough implant surface topographies increase osteogenesis by reducing osteoclast formation and activity. J Biomed Mater Res A 2004;70:361-369.

16. Franchi M, Fini M, Martini D, et al. Biological fixation of endosseous implants. Micron 2005;36(7-8):665-671. Epub 2005 Sep 6.

17. Shibli JA, Mangano C, D'avila S, et al. Influence of direct laser fabrication implant topography on type IV bone: A histo-morphometric study in humans. J Biomed Mater Res A 2010 May;93(2):607-614

18. Güven SS, Cabbar F and Güler N. Local and systemic factors associated with marginal bone loss around dental implants: a retrospective clinical study.Quintessence Int. 2020; 51: 128-141.

19. Astrand P, Engquist B, Anzen B, Bergendal T, Hallman M, Karlsson U, Kvint S, Lysell L, Rundcrantz T. Nonsubmerged and submerged implants in the treatment of the partially edentulous maxilla. Clin Implant Dent Relat Res 2002;4:115-127.

20. Wennstrom JL, Ekestubbe A, Grondahl K, Karlsson S, Lindhe J. Oral rehabilitation with implant-supported fixed partial dentures in periodontitis-susceptible subjects. A 5-year prospective study. J Clin Periodontol 2004; 31:713-724. 
21. Froberg KK, Lindh C, Ericsson I. Immediate loading of Branemark System Implants: a comparison between TiUnite and turned implants placed in the anterior mandible. Clin Implant Dent Relat Res 2006;8:187-197.

22. Esposito M, Ardebili Y, Worthington HV. Interventions for replacing missing teeth: different types of dental implants. Cochrane Database Syst Rev 2014;22:7:CD003815.

23. Moberg LE, Köndell PÅ, Sagulin GB, Bolin A, Heimdahl A, Gynther GW. Brånemark System and ITI Dental Implant System for treatment of mandibular edentulism. A comparative randomized study: 3-year follow-up. Clin Oral Implants Res 2001;12:450-461.

24. Åstrand P, Engquist B, Dahlgren S, Gröndahl K, Engquist E, Feldmann H. Astra Tech and Brånemark system implants: a 5-year prospective study of marginal bone reactions. Clin Oral Implants Res 2004;15:413-420.

25. Schincaglia GP, Marzola R, Scapoli C, Scotti R. Immediate loading of dental implants supporting fixed partial dentures in the posterior mandible: a randomized controlled splitmouth study--machined versus titanium oxide implant surface. Int J Oral Maxillofac Implants 2007; 22:35-46

26. Calvo-Guirado J, Moreno GG and Salvatierra AA, et al. Bone remodeling at implants with different configurations and placed immediately at different depth into extraction sockets. Experimental study in dogs. Clin. Oral Impl. Res. 2015; 26: 507-515

27. Tran, B.L., Chen, S.T., Caiafa, A., Davies, H.M. \& Darby, I.B. Transmucosal healing around peri-implant defects: crestal and subcrestal implant placement in dogs. Clinical Oral Implants Research. 2010; 21: 794-803.

28. Schrotenboer J, Tsao YP, Kinariwala V, Wang HL. Effect of microthreads and platform switching on crestal bone stress levels: a finite element analysis. J Periodontol 2008; 79:2166-72.

29. Meric G, Erkmen E, Kurt A, Eser A, Celik G. Biomechanical evaluation of a fiber-reinforced composite prosthesis supported by implants with and without a microthread collar design. J Dent Sci 2010; 5:201-8

30. Hudieb MI, Wakabayashi N, Kasugai S. Magnitude and direction of mechanical stress at the osseointegrated interface of the microthread implant. J Periodontol 2011; 82:1061-70

31. Van de Velde T, Collaert B, Sennerby L, De Bruyn H. Effect of implant design on preservation of marginal bone in the mandible. Clin Implant Dent Relat Res 2010; 12:134-41.

32. Van Assche N, Pittayapat P, Jacobs R, Pauwels M, Teughels W, Quirynen M. Microbiological outcome of two screwshaped titanium implant systems laced following a splitmouth randomised protocol, at the 12th year of follow-up after loading. Eur J Oral Implantol 2011; 4:103-16.

33. Kang YI, Lee DW, Park KH, Moon IS. Effect of thread size on the implant neck area: preliminary results at 1 year of function. Clin Oral Implants Res 2012; 23:1147-51.

34. Wenzhi Niu, Wang P, Shaoyue Zhu, Zongxiang Liu, and Ping Ji. Marginal bone loss around dental implants with and without microthreads in the neck: A systematic review and meta-analysis. J Prosthet Dent. 2017; 117:34-40. 